\title{
Use, Prevalence and People's Attitude towards Traditional Medicine in Outpatient Department Setting of a Tertiary Care Hospital in Northeast India
}

\author{
Anitha Jose Subin \\ Research Scholar, Department of Pharmacy Practice, JJTU, Rajasthan, INDIA.
}

\begin{abstract}
Objectives: Present study is aimed at reporting the use and people's attitude towards the traditional system of medicine for their medical emergencies or common ailments. Methods: Study was done in outpatient departments of Guwahati Medical College, Assam. Study design was hospital based cross-sectional study, carried out for a period of 4 months. Patients attending outpatient departments were included in the study. A survey using openand close-ended questionnaire was used to collect the data. Questionnaire survey data was entered in Excel spreadsheets and summarized and reported in Figures and Tables. Results: Out of the 259 total participants, 172 $(66.41 \%)$ respondents consulted allopathic practitioners more than 3 times for diseases they suffered last year. Minority population (18.9\%) had consulted traditional medicine practitioners during the last year. Moreover, $62 \%$ never consulted a traditional system practitioner during the previous year. Study proved that easy improvement of physical health $(25.86 \%)$, speedier actions of allopathic medicine (11.58\%), lack of improvement of their health problems by using alternative medicinal system $(7.72 \%)$ and availability of free medicines in the tertiary hospital they visit $(1.93 \%)$ as the reasons for increased use of allopathic system. A very small percentage $(8.88 \%)$ of people opinioned that traditional system is best, because of the lack of side effects and suitability of traditional medicinal system in treatment of common ailments. Conclusion: It is clear from the study that traditional system of medicine didn't acquire its popularity among commoners in Assam even though many of the developed countries partially or fully support such medicinal systems.
\end{abstract}

Key words: Complementary and alternative medicine, Prevalence, Traditional medicine use, World Health Organization, Outpatient department, Assam.

\section{INTRODUCTION}

Traditional Medicine (TM) occupies an important place in the health care systems of developing countries. The WHO estimates that more than $80 \%$ of health care needs in these countries are met through traditional health care practices. Interest in Traditional Medicine is growing rapidly all over world. ${ }^{1}$ This interest is driven by a combination of factors including recognition of potential benefits of TM; dissatisfaction with the traditional Western medical model; an increasing commitment to holistic care and increasing evidence for the interaction of psychological factors and outcomes of disease and treatment and health consumer demand and finally the cheap and easy accessibility. $^{2}$
Customary frameworks of medication incorporate a patient-based indicative framework, an order of infection cycles and elements and a summary of medicines or mediations which address these problems through techniques for natural control (attire, atmosphere and disinfection), diet, actual work, mental preparing and the more energetic intercessions of therapeutic and medical procedure.

Traditional system of medicines is basically situated in a concept of total well-being of patient without considerable side effects. Out of which the predominant ones include 'Ayurveda's which means 'Science of Life', Yoga science as well an art of living healthy,
DOI: 10.5530/ijopp.14.2.25

Address for correspondence: D. Anitha Jose Subin, Research Scholar, Department of Pharmacy Practice, JJTU, Rajasthan, INDIA.

Phone no: +971562563836 Email id: anitha939@gmail.com

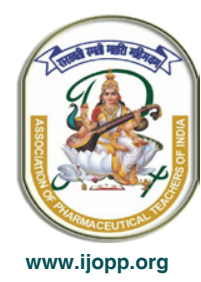


physically, mentally, morally and spiritually, naturopathy a system of healing science that stimulates the body's inherent power to regain health with the help of five great elements of nature - Earth, Water, Air, Fire and Ether, Unani system of medicine is one of the oldest in the world but still popular and practiced in the Indian subcontinent and other parts of the world with specialization in Iatro-chemistry and Homoeopathy, ${ }^{3}$ a rapidly growing system and is being practiced almost all over the world. TCM also includes a wide range of therapies, the bestknown including acupuncture. ${ }^{3}$

In spite of being a compelling arrangement of medication, because of elements of restricted training on practice, social predisposition and political and financial factors, most experts have restricted their training to subsets of the traditional medicine in a different way or modern medicinal system. So traditional systems of health care, dealing with both the preventive and curative aspects of such knowledge is generally limited to the members of a group who have undergone specialized training and/or initiations and who are provided a special status or role as acknowledged healers or physicians by the established culture.

By integrating TM and CM into the official health care system there would be an increase in manpower that could provide a higher degree of health coverage (World Health Organization, 1978). The most effective way of extending benefits without great cost is to use and develop local resources (Teh, 1998). To integrate these two medical systems, there would be need forth TMPs to undergo basic training in orthodox health care practices. Traditional Medicine encompasses a body of knowledge linked to natural resources, specifically biodiversity. Successful integration of TM into the mainstream health care delivery system requires an understanding of patients about the same TM. Local people's attitudes towards TM and its practitioners need to be studied to assess the status of TM and its viability. Furthermore, detailed studies of TM are especially important to inform health policy makers of the role of TM in order to promote it (World Health Organization, 1978).

Therefore, it is appropriate to study the people's understanding and their attitude and knowledge towards the alternative or traditional systems of medicine. Here we explore the practice of and the role of traditional medicine in patient attending a hospital facility in Guwahati city, Assam.

\section{MATERIALS AND METHODS}

Study was done in outpatient departments of Guwahati
Medical College, Assam. Study design was hospital based cross-sectional study. The study was carried out for a period of 4 months. Patients attending outpatient departments irrespective of the specialities of their visit were included in the study. Patients giving incomplete information are excluded from the study. There are many outpatient departments in Guwahati Medical College. Daily attendance in these out-patient departments is found to be a minimum of 115 . Patients coming to medicine outpatient department in Guwahati Medical College was only included in the study. Study was carried out 3 days weekly. Those patients who meet the study criteria were enrolled into the study. Consent was obtained from the authorities of Guwahati Medical College and individuals before the study. A survey employing semistructured interviews and a guided open- and closeended questionnaire was used to collect the data. An easily understandable and comprehensive questionnaire was made which cover patient demographics, questions about patients' choice of preference, morbidity profile for which he/she consulted the doctor in Guwahati Medical College, patients' last year attendance to both traditional and allopathic practitioners and understanding about advantages of traditional system of medicine. The informants were selected purposively and no appointment was made prior to the visits.

Most patients agreed to participate after all ethical issues and purposes of the survey were explained in detail. Only a few refused to give consent, mainly because of lack of time and personal reasons. Patients not giving consent were excluded from the study and were replaced by new participants.

Questionnaire survey data was entered in Excel spreadsheets. It was checked and edited for errors. Thereafter, it was summarized and reported in Figures and Tables. Interview data was studied and the responses were grouped into classes expressing similar ideas. The interview data helped to complement and explain the questionnaire data.

\section{RESULTS}

Total number of 259 patients was included in the prospective study for a period of 4 months in a tertiary care service hospital. General information of the respondents is given in Table 1 . The morbidity profile for which patients sought medical help is studied. Upper respiratory tract infections constitute the major proportion followed by illnesses related to gastrointestinal system to the least common diseases related to blood and musculoskeletal systems. 
Table 1: General Information of the Respondents.

No. of $\%$ of

Age Distribution Respondents Respondents

$<25$ Yrs.

67

25.87

25-45 Yrs

141

54.44

$>45$ Yrs.

51

19.69

Total

259

100

Sex Distribution

Male

67.57

Female

32.43

Total

259

100

Marital Status

Married

160

61.78

Unmarried

99

38.22

Total

259

100

Socio-economic Status

Above average

140

54.05

Below average

119

45.95

Total

259

100

\section{Educational Background}

Illiterate

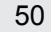

19.31

Primary

High school

Higher secondary and above

Total

119

45.95

259

100

\section{Approximate Distance}

Travelled

$\begin{array}{ccc}<5 \mathrm{Km} & 70 & 27.03 \\ 5-10 \mathrm{Km} & 39 & 15.06 \\ >10 \mathrm{Km} & 150 & 57.92 \\ \text { Total } & 259 & 100\end{array}$

It appears that people prefer allopathic system for the management of various diseases they encounter. All the patients participated in the study had one-mind opinion that they prefer allopathic system in case of medical emergency. However, in case of common ailments they prefer other medicinal systems including Ayurveda and homeopathy. 172 (66.41\%) respondents revealed the fact that they consulted allopathic Practitioners more than 3 times for diverse diseases they suffered last year. It is noticeable that only minority population (18.9\%) enrolled in the study had consulted traditional medicine Practitioners during the last year. Moreover, a large group of patients, say around $62 \%$ never consulted a traditional system Practitioners during the last year, which indicates the familiarity of allopathic system among the patients attending Guwahati Medical College Medicine outpatient department.
Table 2: Various reasons of preference of allopathy among study population.

\begin{tabular}{|cc}
\hline $\begin{array}{c}\text { Reasoning behind the preference } \\
\text { for allopathy }\end{array}$ & $\begin{array}{c}\text { Number of patients } \\
\text { with that opinion }\end{array}$ \\
\hline $\begin{array}{c}\text { Improvement of physical health with } \\
\text { allopathy }\end{array}$ & 67 \\
$\begin{array}{c}\text { Speedier action of allopathic } \\
\text { medicine }\end{array}$ & 30 \\
$\begin{array}{c}\text { Traditional medicine does not } \\
\text { improve disease conditions }\end{array}$ & 20 \\
Availability of free medicines & 5 \\
Don't know & 114 \\
\hline $\begin{array}{c}\text { Reasoning behind the preference } \\
\text { for traditional medicine systems }\end{array}$ & $\begin{array}{c}\text { Number of patients } \\
\text { with that opinion }\end{array}$ \\
\hline Lack of side effects & 15 \\
Appropriate for common ailments & 8 \\
\hline
\end{tabular}

PATIENTS'CHOICE OF MEDICINAL SYSTEM IN COMMON AILMENTS

allopathy ahomeopathy =ayurveda

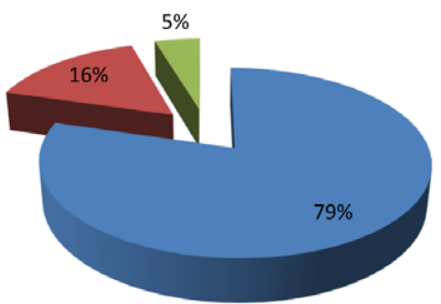

Graph 1: Patient's choice of medicinal system in common ailments.

One hundred and forty respondents (54.05\%) are well aware of the alternative medicinal practitioners in their vicinity. But a huge group of $230(88.8 \%)$ say that they cannot afford cost of traditional medicines. Besides this, they prefer allopathic system over other medicinal systems because of many reasons like easy improvement of physical health $(25.86 \%)$, speedier actions of allopathic medicine $(11.58 \%)$, lack of improvement of their health problems by using alternative medicinal system $(7.72 \%)$ and availability of free medicines in the tertiary hospital they visit $(1.93 \%)$. A very small percentage $(8.88 \%)$ of people appealed that traditional system is best, because of the lack of side effects and suitability of traditional medicinal system in treatment of common ailments.

\section{DISCUSSION}

The interest in herbal and other traditional medicines and the usage of herbal or traditional system was rapidly growing in recent years. ${ }^{4}$ The main objectives of this study were to assess the knowledge and perceptions of 
patients with respect to alternative systems of medicine. This was to understand the degree of awareness of commoners visiting outpatient departments of Guwahati Medical College whereas many developing countries totally or partially depend upon traditional and herbal medicines for alleviation of symptoms and cure.

Around $79 \%$ of total study population favors allopathic system of medicine whereas $21 \%$ considers alternative systems of medicine as better choice, $16 \%$ and 5\% from homeopathy and Ayurveda respectively (Graph 1). However, the interesting finding in this study was that no respondent found who favor siddha medicine system which is contrary to the finding of a Tamil Nadu based study. Obviously, the difference is due to change of modality. Worldwide studies highlight the use of CAM alone and CAM with allopathic medicine by large majority of population, ${ }^{5}$ but results in present study are distinguished since only less than $1 \%$ considers CAM as best medicinal system.

Although earlier studies proved that, there exists a significant association between CAM practice and educational background and CAM practice and socio-economic position, ${ }^{6}$ present study proves that people prefer modern medicinal system irrespective of their educational background as well as socio-economic position.

It appears that people prefer allopathic system for the management of various diseases they encounter. 172 respondents revealed the fact that they consulted allopathic practitioners more than 3 times for diverse diseases they suffered last year. It is noticeable that only minority population $(18.9 \%)$ enrolled in the study had consulted traditional medicine practitioners during the last year. Moreover, a large group of patients, around $62 \%$ never consulted a traditional system practitioner during the last year, which indicates the familiarity of allopathic system among the patients attending Guwahati Medical College outpatient departments.

Accessibility to alternative medicine practitioner was satisfactory as per the opinion of respondents; say about $54 \%$ people said that there are alternative medicine practitioners in their area. But $12.7 \%$ had no easy accessibility for the same. $29.3 \%$ are not at all aware about the service of alternative practitioners in their nearby areas.

During acute illness or medical emergency, patients alternatively use traditional medicinal systems and modern medicine systems hoping that a care will come from one or both of them. ${ }^{2}$ Some studies proved that Despite overall incline to herbal medications, the Allopathic scheme still relics the initial system up on which the people relay and Ayurveda in case of common ailments. ${ }^{7}$ Almost all the patients participated in the present study had one-mind opinion that they prefer allopathic system in case of medical emergency. However, in case of common ailments they prefer other medicinal systems including Ayurveda and homeopathy and the percentage of preference is $5 \%$ and $16 \%$ respectively.

Reasoning of the patients who supports allopathic and traditional medicine systems was checked. It is clear from the study that a large majority of people doesn't know why they prefer a medicinal system and what advantage a specific system can bring to him/her. Contemporary medication fetched some development in health problems but was unsuccessful to treat the primary problem. ${ }^{8}$ It is also worth noting that $26 \%$ people believe that modern medicinal system can improve their physical health considerably which differs considerably from the studies conducted. ${ }^{9}$ Even though a very small percentage of people appealed that traditional system is best, where a minority prefer it because of the lack of side effects, which strongly supports the former studies done earlier. ${ }^{10,11}$

Studies that had already done over this matter brought out the general opinion of the public are tilting towards use of herbal drugs. The gradual rise in trade of these drugs in all over the world stands testimony to this. Public seems to be fed up with Synthetic drugs primarily because modern medicine give only indicative relief is experienced. 'Completion of treatment or complete cure from the disease' is not ever a certainty, more so in long-lasting illnesses. Earlier study ${ }^{12}$ that frustrating side effects and high cost involved contributes a non-minor reason. But contrary to this the respondents of our study opinioned that they prefer allopathy since improvement of physical health experienced by the use allopathy, speedier action of allopathic medicine, availability of free medicines in government hospitals and unsatisfactory improvement in disease condition by the use of old-style medication.

\section{CONCLUSION}

It is clear from the study that traditional system of medicine didn't acquire its popularity among commoners in Assam even though many of the developed countries partially or fully support such medicinal systems. Patient education at the level of pharmacists or doctors regarding the implications of concomitant use of complementary medicines in case of at least chronic health issues is needed in the optimization of holistic healthcare in the country especially in Middle East India.

Indian Journal of Pharmacy Practice, Vol 14, Issue 2, Apr-Jun, 2021 


\section{ACKNOWLEDGEMENT}

Dedicated to all the population who patiently co-operated with the study despite their diseases. Also, we would like to thank the entire Pharmacy Practice department of NIPER, Guwahati. A word of special thanks to Dr. Sapna D. Kakoty and Mr. Arvind Kumar Katariya for their help in protocol and conduct of the study.

\section{ETHICAL APPROVAL}

Institutional Ethics Committee of Gauhati Medical College and Hospital. No. MC/190/2007/Pt-1/47 dated 10 January 2021.

\section{CONFLICT OF INTEREST}

The author declares there is no conflict of interest.

\section{ABBREVIATIONS}

CAM: Complementary and alternative medicine; WHO: World Health Organization; TM: Traditional Medicine; AM: Alternate Medicine; OPD: Outpatient Department.

\section{REFERENCES}

1. Tabuti JRS, Dhillion SS, Lye KA. Traditional medicine in Bulamogi County, Uganda: its practitioners, users and viability. J. Ethnopharmacol. 2003;85(1):119-29.
2. Pang KY. The practice of traditional Korean medicine in Washington D.C. Soc Sci Med. 1989;28(8):875-84.

3. Bishop FL, Lim CY, Leydon GM, Lewith GT. Overseas Chinese students in the UK: Patterns and correlates of their use of Western and traditional Chinese medicine. Complement Ther Clin Pract. 2009;15(1):8-13.

4. Majumder A. Utilization of Health Care in North Bengal: A Qualitative Study on Preference for a Care with Respect to Type of Facility and System of Medicine. Anthropol. 2006;8(1):33-41.

5. Pilkington K, Kirkwood G, Rampes H, Fisher P, Richardson J. Homeopathy for anxiety and anxiety disorders: A systematic review of the research. Homeopathy. 2006;95(3):151-62.

6. Davidsona P, Hancocka K, Leungc D, Angd E, Changa E, Thompson DR, et al. Traditional Chinese Medicine and heart disease: What does Western Medicine and nursing science know about it. Eur J Cardiovasc Nurs. 2003;2(3):171-81.

7. Kumar D, Bajaj S, Mehrotra R. Knowledge, attitude and practice of complementary and alternative medicines. Public Health Rep. 2006;120(8):705-11.

8. Singh V, Raidoo DM, Harries CS. The prevalence, patterns of usage and people's attitude towards complementary and alternative medicine (CAM) among the Indian community in Chatsworth, South Africa. J Altern Complement Med. 2004;4(3):1-7.

9. Jawla S. Gupta and homeopathic systems. J Chem Pharm Res. 2009;1(1):105-12.

10. Ramesh A, Hima B. Traditional Indian AK, Singla R, Gupta V. General awareness and relative popularity of allopathic, ayurvedic medicine in practice in an Indian metropolitan city. Soc Sci Med. 2009;15(D):69-81.

11. Evans A, Duncan B, McHugh P, Shaw J, Wilson C. Inpatients' use, understanding and attitudes towards traditional, complementary and alternative therapies at a provincial New Zealand hospital. N Z Med J. 2008;121(1278):21-34.

12. Krishnan A, Bagyalakshimi P, Ramya S, Jayakumararaj. Revitalization of Sidha medicine in TamilNadu, India-changing trends in consumer's attitude: A survey. Ethnobotanical Leaflet. 2008;12(1).1246-51. 